\title{
Using BIM to automate construction site activities
}

\author{
H. S. Omar \& M. F. Dulaimi \\ British University in Dubai, United Arab Emirates
}

\begin{abstract}
Controlling construction site operations is one of the crucial overriding concerns for the clients and contractors, as the majority of the construction delays tend to occur in the construction phase. It is not surprising to see interest in deploying advanced technologies such as Building Information Modelling (BIM) to help in addressing such concerns.

The purpose of this paper is to investigate how to integrate BIM with the daily construction activities to increase the effectiveness of construction operational activities and address customers and clients concerns and requirements.

The study adopted the qualitative approach to collect the data from different construction sites. Clients and numerous members of the supply chain were involved in the data collection, which covered projects, in United Arab Emirates (UAE), such as real estate building, infrastructure (e.g. water and waste water) and road projects.

The study concluded that, integrating BIM in the reoccurring daily construction operations highly assisted the construction industry to overcome several persisting and challenging problems related to the traditional disputes and mistrust among the supply chain players. These disputes resulted from the inaccurate data collection that leads to the absence of crucial actions, in addition to the huge time consumed to prepare reports. The results of the study suggest that, the integration of BIM with the construction operational activities have improved productivity and enhanced the trust among the project teams. Furthermore, the automation of the construction site activities using BIM avoided loss of information, enabled contractors to recognize their weaknesses, enabled immediate update of the progress reports and the program of works and the easy production of the payment statement.

Keywords: BIM, automation, productivity, integration, transparency and trust.
\end{abstract}




\section{Introduction}

For decades the construction industry has been challenged to improve its efficiency with myriads of different initiatives. These initiatives aiming to improve the construction industry sub-optimal outcomes resulted from the fragmented way in which the construction industry operates [1]. Mitropoulos and Tatum [2] explained that, advances in technology are widely regarded as major sources of improvement in the construction industry. Hence, adoption of new suitable technology could be crucial to assisting the construction industry in overcoming many of its recognized problems. At the moment BIM is rapidly growing in importance and mandating the construction industry worldwide as a viable tool to overcome the majority of the reoccurring and persisting problems in the construction industry [3]. Although BIM is widely utilized since 2002 [4] site management works is still dominated by traditional paper works especially the manual recoding of the notes for the on-site activities [5]. Site managers and inspectors manually collect and record the progress of the site activities, the collected records have to be re-entered at the site office [6]. During this processes, site managers and inspectors (the data feeders) always make mistakes. Moreover, this is a time consuming process which takes approximately $20-30 \%$ of the feeders' daily efforts to update the construction activities [7, 8]. This traditional site monitoring and updating system entails numerous weaknesses such as missing or wrong information. Thus, the Project Manager (PM) is not furnished with the authenticated and reliable construction progress details. Therefore, many crucial actions for critical activities are absent [9]. This confusion in many cases could lead to PMs' misjudging what the actual progress is in their projects, and accordingly to inappropriate decisions being made that could impact the effectiveness of the use of resources. For example, based on the traditional progress monitoring system, PM may judge an activity to be only $30 \%$ completed even it is actually $60 \%$ completed. In this case, PM may believe that the construction project is delayed, even though it is proceeding ahead of the planned schedule. Consequently, the PM will deploy more resources to that activity than is necessary required which result in waste of time and money [6]. It is obvious; the current manual system for updating and monitoring the site activities tends to create uncertainties that lead to client's dissatisfactions. Therefore, the data collection system requires extensive improvement to collect the actual data [10]. The importance of construction site checking and automatic updating has been recognized before the advent of BIM, this topic has been investigated in 1960s [7]. Many researchers proposed numerous of initiatives to automate the monitoring and checking processes of the construction site activities on the bases of zero or minimal human intervention $[11,12]$. This paper considered the automation of the construction site checking and updating in two levels. First level: where the human intervention required to visually check the status of the on-site construction activity(s) based on a ready-made check list that is unique to suit each task. The check list is linked to the BIM model that is furnished to the Personal Digital Assistants (PDA) devices such as tablets or smartphones for the on-site inspector's easy use. The collected data will be automatically sent via the internet to the server 
to be stored and automatically updated using the cloud BIM model. The cloud BIM model is originally an identical copy of the designed BIM model that made ready to receive the update from the site. The second level is to automatically update of the progress by comparing the created BIM cloud model against the designed 3D and 4D BIM final model with no intervention from humans. At this level, the automated system can identify the construction mistakes based on 3D BIM model, and the activities that are deviated from the planned construction schedule based on 4D BIM model. The system will automatically notify the concerned parties through sending mails for the required actions. The aim of this paper is to integrate BIM's potential with the available technology of PDA in a rigorous controlled manner. That is to achieve $100 \%$ accuracy of the construction monitoring and updating, in addition to rein on project delays resulted from the inaccurate site data collection.

The literature review unveiled many endeavors proposed to automate the checking process of the construction sites using the recognized technologies such as bar coding or may be called also Quick Response-code (QR-code), BIM, Augmented Reality (AR), Global Positioning System (GPS), photogrammetry, Radio Frequency Identification (RFID), Laser scanner (LS) and wireless sensors [12-18]. Most of these initiatives considered the full automation of the processes where the intervention of human element is very limited [8, 11]. The human intervention is determined to carry, scan and point the electronic devices to collect the data from the construction sites $[17,19]$. However, these initiatives entail myriads of challenges that hindered reaping its full benefits $[8,11]$. Accordingly, the accuracy of these proposals varies and heavily dependent on several factors, such as the used technology, the project's level of sophistication, the familiarity with the new initiative, etc. These factors and their relevant limitations are detailed hereunder section 1.1 .

It is worth mentioning that, the verification and judgment of the accuracy for the proposed automated initiative is conducted by the traditional checking i.e. by the human element. Therefore, it is obvious the human element is reliable; however the dilemma represented in the unsystematic procedures which leads to loss of data or mistakes in addition to time consuming [14].

The following section addresses the latest and most recognized initiatives that attempted to automatically monitor and update the on-site construction activities.

\subsection{Previous attempts of the on-site automation}

\subsubsection{Augmented Reality (AR)}

$\mathrm{AR}$ is one of the techniques used advanced technology to automatically update the site activities to detect the differences between the design and the actual construction. There are several definitions for the AR; AR is defined as the technology that is used to ease associating the digital information with real world objects and spaces [12]. According to Madden [20] AR is an environment where virtual elements are embedded in a live picture of real surroundings. However, the most comprehensive definition proposed by Azuma [21] where he defined AR as an interface that overlays the digital information and presents it to the user's view, spatially aligned to the current physical environment. 
There are several AR systems; however the hub of the latest initiatives of proposed AR that is utilized BIM can be summarized as follows $[12,17]$ :

1. The 3D BIM model introduced to the construction site superintendents via PDA such as tablets or smartphones.

2. The site superintendents use the built-in camera of the PDA devices to capture site photos for the actual constructed works. The captured photos will be sent through the PDA devices that are supported by internet wireless connections to the image-matching system via server installed and connected in the office.

3. The image-matching system automatically compares the captured site photos against the final BIM model to find out any differences. Any discrepancies between the actual constructions and the BIM model will be highlighted and the system will automatically send a notification to the concerned person, according to the rule created in the system.

4. Last few years witnessed further improvement done to the system, that proposed installing cameras to cover the site activities, in order to capture the on-site activities without the intervention of the site superintendents and there is no need to visit the job-site [22].

It is obvious, AR composed of three elements, data, computing and presentation [12]. AR is unlike many other technologies proposed to automate the site activities; AR hub is about displaying the virtual information based on the BIM model in a real-world environment for necessary actions [22].

Originally, AR was not proposed to automate the construction activities; however it is developed to benefit the automation in construction by detecting the construction defects. Therefore, it is obvious to update the construction activities a massive number of site photos are required. Following are the most recognized limitations and challenges that hinder the wide adoption of AR to automate the monitoring of the construction activities.

1.1.1.1 Challenges of the AR Cameras often encounter difficulties in detecting the indoor objects because of the indoor poor lighting. Similarly, due to the dynamic nature of the construction site there is difficulty in capturing the actual status for the covered activities with temporary works such as scaffolding or frameworks and so forth. The AR image-matching system can't work properly to run the comparison for the unclear photos or the photos encompass any temporary works [17]. In addition to that, the camera's shooting location, height and viewing angle. Moreover, the lighting levels, the camera resolution and the distance between the camera and the objects are factors influencing the data collection and the results of the AR outputs [17]. Some AR approaches are using GPS to position the construction objects; however the accuracy is poor, where GPS errors is in centimeters and sometimes in meters [12].

\subsubsection{Radio Frequency Identification (RFID)}

RFID defined as a wireless technology capable of the automatic identification of objects and even people based on tags entail the data for the objects and people. RFID is a contactless technology that operates without line-of-sight restrictions [23]. In this technology the RFID contains a reader that is used to collect data from 
tagged coded objects. The tagged objects must be unique to avoid any data mix and misleading results. RFID enables tracking of a product and hence monitoring its performance by running an automatic comparison between the actual collected data from the site and the planned program of works [24]. In order to enhance the capability of the RFID system, the entire activities within the site should be covered with a network of RFID readers to collect the data from the tagged objects and then transmit these data to a database system that can translate these codes to activities [23]. Many researchers proposed integrating RFID with BIM to automatically update the site activities [23, 25]. This initiative seen promising, however it is compounded with challenges that deters its potentiality. Following are the most recognized challenges for RFID approach.

1.1.2.1 Challenges of RFID The data collection process from the tagged objects requires covering the entire site with RFID readers. Therefore, any damage in the tags for the tagged objects due to the dynamic nature of the site or malfunction of the reader, hence no data will be transmitted to the system which will be useless [23].

RFID tags have a small radio antenna that transmits the information over a short range to RFID reader (few meters), accordingly big number of RFID readers are required to transmit the data effectively [26].

RFID uses radio frequency, therefore the interference with any other frequencies could diminish its capability to transmit the data effectively.

Complex or partial activities that consisted of irregular surfaces, cavities or grooves cannot be appropriately determined by the RFID system.

Temporary installed equipment/works negatively impacts the results of the RFID, where the temporary works hamper the waves to scan the tagged codes [14].

The price of the RFID still very high, moreover the selection of the required tags, weather to be passive or active type is a sophisticated technological issue [14].

\subsubsection{D Laser scanning (LS)}

LS may be dubbed also as Laser Distance and Ranging (LADAR). LS defined as high-end laser scanner that collects physical data from the construction site for the existing objects/activities using the technology of laser light together with advanced reflectors. That is to create as-built model with 3-6mm accuracy [11, 27]. Many studies proposed using the 3D LS technology where the laser light triggers the surrounding to scan the construction activities, which will be reflected on sensitive devices to create $3 \mathrm{D}$ point clouds. Then, all the collected data are merged together to form as-built model. The merged 3D as-built model is then manually entered to the system to avoid any misidentification of the similar objects, where the system can't differentiate or classify many items due to the similarity of the construction elements. In the second stage the system automatically detects any progress deviations by comparing the as-built model with the planned progress model [11].

A recent study by Bosché [11] proposed integrating the as-built model that is developed by the LS approach with the 3D BIM model (the designed as-built model) in a semi-automated process where the human intervention is crucially 
required. That is because; the fully automated process is not applicable in the construction industry due to the similarities of the scanned objects where the system can't recognize the relevant objects automatically. Brilakis et al. [28] claimed that, LS technique is heavily reliant on manual efforts. Many studies proposed using LS together with BIM model to compare the construction progress via the 4D BIM model against the cloud as-built model that is developed from the LS approach to detect any deviations of the planned schedule [11]. LS currently is the most recognized $3 \mathrm{D}$ reality capturing method in the construction industry, however this technique challenged with numerous limitations impedes its widespread utilization $[8,11,27]$.

1.1.3.1 Challenges of laser scanning The most popular challenge of the LS is the discontinuity of the spatial information, where the laser scanning process can detect only the exposed objects/activities. Whereas, the temporary objects such as scaffolding, equipment, temporary structures and so forth hinder the authenticated data collection [11].

The data collection process is a time consuming which also requires experienced surveyors that use bulky machines need to be manually moved and positioned [27].

The scanning range is limited, the object's surface degree of reflectivity, the angle of measurements and sensor calibration are important factors influence the accuracy of the collected data [8].

During the adverse weather (e.g. rainfall, wind, etc.) the scanning process can't be conducted [8].

The laser scanning matching mechanism is lacking the recognition of the objects of self-similarities; therefore huge manual efforts are required [11].

The cost of the laser scanning devices and the related software and hardware are expensive [8].

\subsubsection{Wireless Sensor Network (WSN)}

WSN is a technology that is using sensor nodes which communicate with each other wirelessly to collect the data from the surrounding environment and share it with the designed model. The updated model with the actual site conditions can be used to automatically asses the deviations between the designed model and the physical as-built (the actual site condition) [29]. In addition, the percent completion of each activity in the construction schedule can be continuously viewed in the BIM 4D model [18]. An extensive study by Riaz et al. [18] proposed solutions to closely monitor the confined spaces in the construction sites through using the wireless sensors to automatically update the 3D BIM model with the collected site hazards. However, this proposal is not tested yet to proof its capacity. WSN like all other recognized automation initiatives are confronted by many challenges. These challenges are addressed as follow:

1.1.4.1 Challenges for wireless sensors The WSN approach is expensive, in addition it needs experts to operate the system properly.

The system is heavily depending on Wi-Fi network to transfer the collected data, thus any poor signal creates discontinuity of the transferred data. 
Transmitting the data over a long distance will cause a false data.

WSN are equipped with batteries, any low battery causes a gap for the data collection in the whole system.

The surrounding weather especially the high ambient temperature negatively impacts the sensors' performance.

A study conducted at the Washington University concluded that the collected data by the WSN is unreliable. The study found that $70 \%$ of the alarms (the automatic response of the collected data) from similar wireless sensors are false [18]. It is obvious all the proposed initiatives to automate monitoring of the construction activities have certain limitations that impede its potential benefits. Therefore, some researchers have integrated two or more of the aforementioned automation approaches to alleviate the limitations associated with each of them individually [30]. For example El-Omari and Moselhi [14] proposed integrating 3D laser scanner with photogrammetry to rapidly track the site activities. The proposed model can automatically calculate the construction percent of completion and track the physical construction progress. The added advantage for the proposed integration between the LS and photogrammetry technique, it requires less time with cost saving compared to the stand-alone application of either LS or photogrammetry. The proposed approach also minimized the limitations of the LS placement by integrating the photogrammetry data with the LS model cloud [8]. Nevertheless, the proposed approach didn't resolve all the challenges that diminish the adoption of this approach in a hassle-free manner [30]. Even the proposed integrated approach has been challenged with certain limitations, where the captured photos are not automatically aligned with the 3D cloud model. In addition, the integration between the data collected by LS and photogrammetry are done manually due to the absence of the sharing algorithm between both approaches. Therefore, the manual integration between both techniques is prone to errors, and time consuming process [8].

The literature review revealed that, all the proposed initiatives to monitor the construction activities are not fully automated and even the fully automated proposed approaches didn't meet the expectations. Moreover all the previous approaches are embedding several challenges and limitations.

\section{The proposed prototype}

The extensive literature study provided a deep understanding for the initiatives that proposed to automate monitoring and updating the construction activities, the correlated limitations and challenges for these initiatives are recognized too. The literature review revealed that, the available technology is lacking the ability to fully automate monitoring and updating processes for the construction industry [11]. Figure 1 presents the proposed prototype, wherein the researchers proposed two levels of processes. First level is the semi-automated process to collect the data from the construction sites using the human element i.e. site inspectors. In this level the data collection is rigorously controlled to eliminate the chances of making mistakes, where the site inspectors use the electronic devices such as smartphones and/or tablets equipped with BIM models. Based on the BIM model 


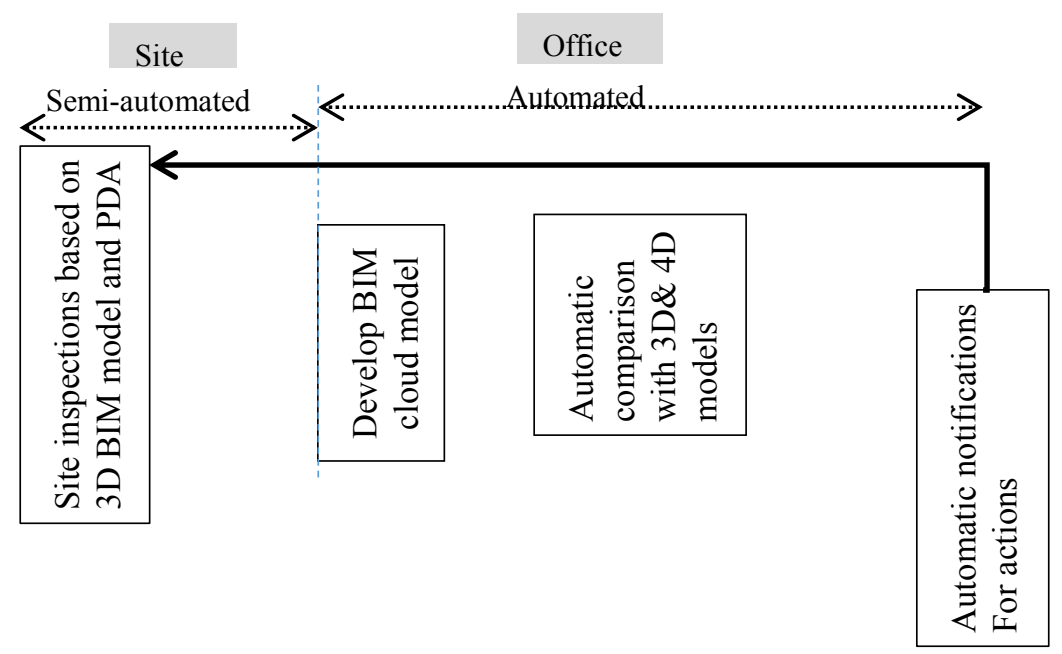

Figure 1: The proposed prototype.

that is available in the PDA devices the inspector is required to check the actual activity. The inspector will be able to on the-spot update the construction status using a unique number for each task that is predefined in the BIM model. Once the inspector clicks-on the task for inspection, the hand-held device will automatically introduce the pre-prepared check-list that is suiting the recognized task. The inspector will be required to fill-in the check list on-site to avoid any errors and to save time. Moreover, the inspector can narrate and review all the previous tests i.e. the test results or the required tests, the uploaded specifications, review the construction method statements, review the previous approvals or comments, all the required details will be available on-site for each task under a unique number via the developed BIM model. In order to complete the process for this level, the inspectors are required to send the collected data via the internet that is connected to the PDA devices to develop the BIM cloud model. The BIM cloud model is originally the designed BIM model that is developed to continuously receive updates for the actual data collected from the site. The second level is fully automated, where the system automatically run a comparison between the developed BIM-cloud model and the as designed 3D and 4D BIM models to recognize any construction mistakes that is deviated from the $3 \mathrm{D}$ model. Concurrent automatic comparison with the 4D BIM model runs to identify any deviation in the planned program of works. The system will consider the delays and ahead of the planned schedule as findings that requires immediate actions from the concerned personnel(s). Therefore, the proposed system/prototype will automatically send notifications to the predefined concerned parties such as PM, client or the supervision team representative(s) according to the rules created in the system. The deviations due to the delays of the planned construction program require immediate actions by the authorized personnel; the system will highlight the delayed activity(s) in addition to the impacted activities. Moreover, the system 
will advise on the required manpower and equipment to be allotted to recover the delays. Similarly, the system will advise the required resources based on the rate of production for the resources that is introduced in the system. All these notifications are based on the automatically developed recovery plan considering the milestone date $(\mathrm{s})$.

\section{Research framework and methodology}

The aforementioned two levels represent the proposed prototype which was extensively discussed with software specialists through semi-structured interviews. The feedback and the proposed modifications from those specialists make the proposed prototype applicable and viable for implementation. Figure 2 demonstrates how the prototype was developed, where the developed prototype is

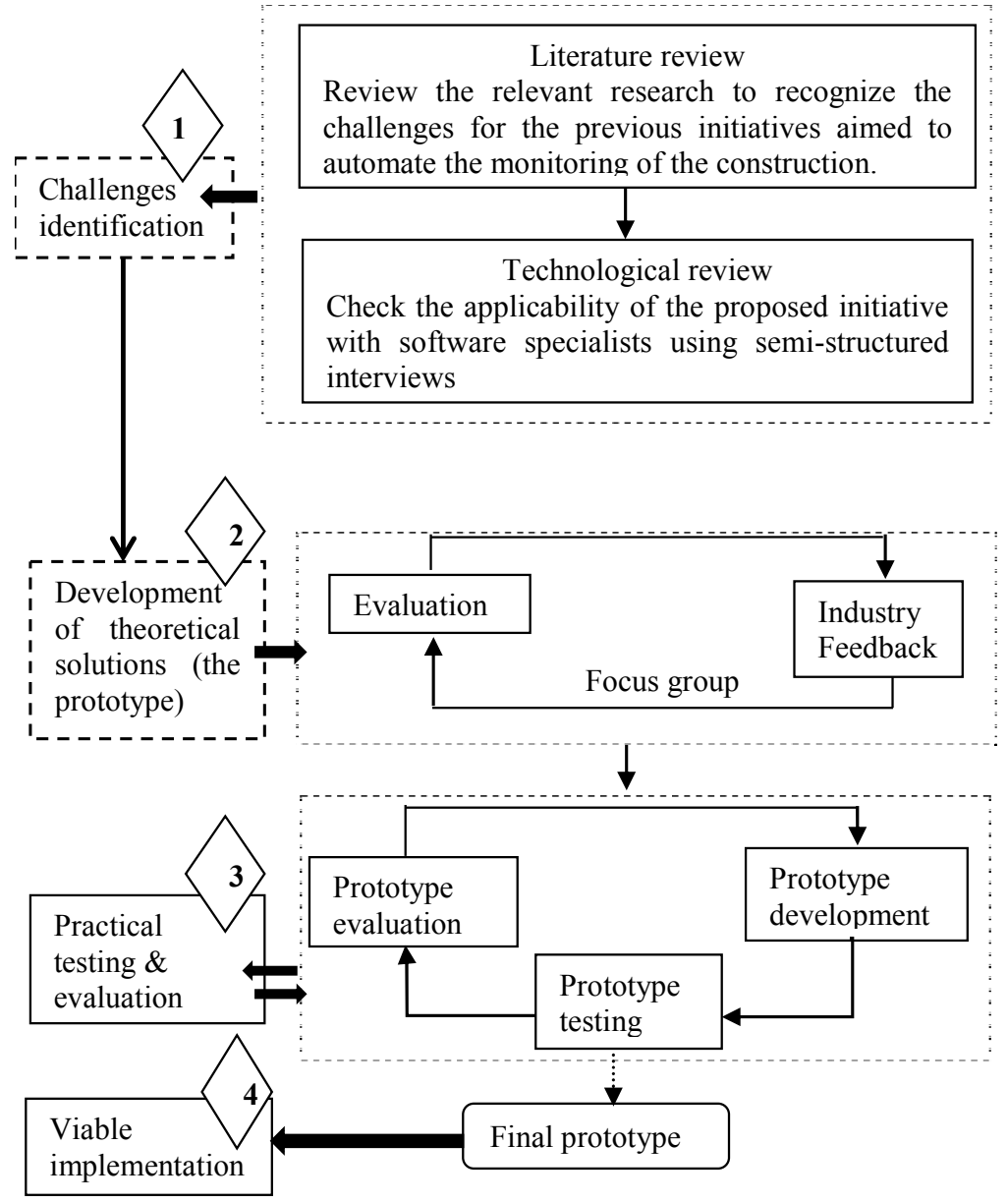

Figure 2: Research framework and methodology. 
presented as stage 1 and 2 in Figure 2. In order to check the viability of the prototype, the researchers found that the next stage should be testing the proposed prototype and evaluating the advantages and disadvantages. Recognizing the prototype limitations enabled the researchers to propose further improvements till the limit the proposed prototype overcome all the recognized challenges to effectively automate the construction monitoring. It is worth noting that, the proposed prototype is evaluated by conducting a focus group discussion of seventeen experienced professionals representing contractors/subcontractors, designers (structure and MEP), site supervisors, clients, suppliers, BIM specialists, in addition to software specialists. The focus group approach was adopted to enable these carefully selected professionals to evaluate the proposed prototype based on their knowledge and experience of the BIM as well as some of the latest automation technologies and the confronted limitations.

The researchers provided a 40 minute presentation on the current automation practices and the correlated limitations and challenges and then explained in details the proposed initiative. The group discussions enriched the research by addressing several challenges, benefits and suggestions that are summarized, in the following Tables 1, 2 and 3 respectively.

Table 1: The proposed prototype challenges according to the group discussion.

\begin{tabular}{|c|l|l|}
\hline Sr. & Challenges & Remarks \\
\hline 1 & $\begin{array}{l}\text { The proposal is heavily dependent on } \\
\text { precise decomposing of the activities } \\
\text { to show the infinitesimal task using a } \\
\text { unique number to be synchronized } \\
\text { with BIM model. }\end{array}$ & $\begin{array}{l}\text { Requires long time and collective work } \\
\text { from all project workforce including all } \\
\text { the supply chain and site } \\
\text { superintendence prior to starting the } \\
\text { site activities. }\end{array}$ \\
\hline 2 & $\begin{array}{l}\text { Any change in the program of } \\
\text { construction requires massive change } \\
\text { and rearrangement of the unique } \\
\text { numbers and the tasks. }\end{array}$ & $\begin{array}{l}\text { Any changes of the program will delete } \\
\text { the affected numbers and use new } \\
\text { numbers to avoid disturbance. The } \\
\text { program will automatically update the } \\
\text { new changes. The initiative based on } \\
\text { BIM designed model. }\end{array}$ \\
\hline 3 & $\begin{array}{l}\text { Preparing a template check list for } \\
\text { cluster of activities is a difficult task. }\end{array}$ & $\begin{array}{l}\text { Requires collaborative work including } \\
\text { all the involved individuals prior to } \\
\text { starting the construction activities. }\end{array}$ \\
\hline 5 & $\begin{array}{l}\text { Synergic issues and algorithms } \\
\text { between BIM cloud model and the } \\
\text { BIM designed model. }\end{array}$ & $\begin{array}{l}\text { Current software capabilities can be } \\
\text { developed to accommodate these } \\
\text { issues. }\end{array}$ \\
\hline 5 & $\begin{array}{l}\text { Site inspectors may lack the } \\
\text { knowledge how to use the PDA } \\
\text { devices. }\end{array}$ & $\begin{array}{l}\text { Cost issues, for the hand-held PDA } \\
\text { devices and internet. }\end{array}$ \\
\hline $\begin{array}{l}\text { Training programs to the site } \\
\text { inspectors. }\end{array}$ \\
\hline $\begin{array}{l}\text { The developed system doesn't need } \\
\text { advanced devices since it relies on the } \\
\text { server storage capacity. Even personal } \\
\text { smartphones can work. }\end{array}$ \\
\hline
\end{tabular}


Table 2: The anticipated benefits for the proposed prototype.

\begin{tabular}{|l|l|l|}
\hline & Benefits & Remarks \\
\hline 1 & $\begin{array}{l}\text { Immediate development of } \\
\text { progress reports. }\end{array}$ & $\begin{array}{l}\text { Time saving, where all the project parties will get } \\
\text { the same report from their offices at no time } \\
\text { based on eligibility access to the system. }\end{array}$ \\
\hline 2 & $\begin{array}{l}\text { Immediate development of } \\
\text { the monthly payments. }\end{array}$ & Save the time and disputes. \\
\hline 3 & Enhance the cost control. & $\begin{array}{l}\text { Appropriate estimation and control of the cash } \\
\text { out/in. Moreover, at any time the progress report } \\
\text { together with costs can be produced. }\end{array}$ \\
\hline 4 & Immediate action. & $\begin{array}{l}\text { The system notifies the concerned personnel with } \\
\text { the required actions. }\end{array}$ \\
\hline 5 & $\begin{array}{l}\text { Enhance transparency and } \\
\text { trust. }\end{array}$ & $\begin{array}{l}\text { The open environment will enhance the trust and } \\
\text { transparency, where the inspection results and the } \\
\text { required actions are seen by the client and } \\
\text { stakeholders. }\end{array}$ \\
\hline 6 & $\begin{array}{l}\text { Client and stakeholders are } \\
\text { continuously updated. }\end{array}$ & $\begin{array}{l}\text { The supply chain can recognize their weaknesses } \\
\text { from the repetitive comments. }\end{array}$ \\
\hline 7 & $\begin{array}{l}\text { Weaknesses and defects } \\
\text { recognition. }\end{array}$ & $\begin{array}{l}\text { That basically benefits the facility management } \\
\text { teams, users and the client. And any parties in } \\
\text { dispute. }\end{array}$ \\
\hline 8 & $\begin{array}{l}\text { Immediate producing of the } \\
\text { as-built including all the } \\
\text { detailed construction history. }\end{array}$ \\
\hline 9 & $\begin{array}{l}\text { Review the history of any } \\
\text { task. }\end{array}$ & $\begin{array}{l}\text { At any time of the project lifecycle the history of } \\
\text { the activities can be easily retrieved/ reviewed. }\end{array}$ \\
\hline
\end{tabular}

Table 3: Suggestions to improve the proposed prototype.

\begin{tabular}{|c|c|c|}
\hline & Suggestions & Remarks \\
\hline 1 & $\begin{array}{l}\text { The system should automatically } \\
\text { notify the inspectors with the } \\
\text { required inspections, including } \\
\text { date and time. }\end{array}$ & $\begin{array}{l}\text { Software specialists confirmed the ability } \\
\text { of the new idea to save time and efforts. }\end{array}$ \\
\hline 2 & $\begin{array}{l}\text { The procurement methodology } \\
\text { should be design and built or IPD. }\end{array}$ & $\begin{array}{l}\text { That significantly reduces the costs and } \\
\text { enhances BIM potential capacity. }\end{array}$ \\
\hline 3 & $\begin{array}{l}\text { The system should have different } \\
\text { levels for approvals of the } \\
\text { inspection to ensure QA. }\end{array}$ & $\begin{array}{l}\text { The inspectors' comments/approval can be } \\
\text { automatically sent for the supervision team } \\
\text { head as a notification and reminder if } \\
\text { required for final approvals after the } \\
\text { material and site inspection approvals. }\end{array}$ \\
\hline 4 & $\begin{array}{l}\text { Detect the gaps in inspection and } \\
\text { consider the logic construction } \\
\text { sequencing. }\end{array}$ & $\begin{array}{l}\text { The prototype must be developed to } \\
\text { considerer the construction logic } \\
\text { sequencing i.e. no painting for walls } \\
\text { without approvals of plaster works. In } \\
\text { addition, detecting the construction gaps, } \\
\text { for example second phase of construction } \\
\text { shouldn't be allowed prior the completion } \\
\text { of the previous phase, i.e. the system } \\
\text { should notify there is a missed inspection } \\
\text { for the second floor's column(s) or the } \\
\text { alike prior to starting any activities for the } \\
\text { third floor. }\end{array}$ \\
\hline
\end{tabular}


It is worth mentioning that, stages 1 and 2 via Figure 2 are completed, however stage 3 is in progress till the time of writing this paper. Stage 4 will be the last stage to advert the final prototype after physical purifications of all its weaknesses.

\section{Conclusion (way forward)}

The paper found that, all the available technologies are lacking the precise automatic data collection from the construction site. Hence, utilization of site inspectors to collect the data in timely manner and free of errors by using the advanced technology such as tablets or smart phones together with checklists is the panacea for this dilemma. Moreover, the proposed prototype significantly minimizes the mistakes during the data collection process, which to be sent to the database of the BIM cloud model. The developed software automatically compares between the actual collected data from the site (e.g. BIM cloud model) against the designed BIM model 3D and 4D to recognize the differences to find out the construction mistakes for the quality control using 3D BIM model. In addition, the prototype will highlight the discrepancies between the planned program via 4D BIM model and the actual status via the BIM cloud model to notify the concerned individuals, by sending mails with the required actions. It is obvious, the proposed prototype can overcome majority of the recognized problems that aimed to automate monitoring of the construction activities. Furthermore, it enhances the transparency and trust amongst the project teams because all the work activities are in an open environment for all the project teams. The proposed initiative saves the time by notifying the required actions and determines the required resources to overcome the delays or to exploit the ahead of progress status. All these notifications to mitigate the delays or exploit the ahead of schedule based on automatically generated recovery program. Using the proposed initiative the progress report and the payment, cash flow in/out is just click away of the finger. Moreover, all the details of all the activities during the project lifecycle can be narrated and supported with the site photos. The proposed prototype seems promising; however the field experiment which will start soon will physically prove its viability in the construction industry. Developing of the proposed prototype software is in progress till the time of writing this paper, which will be tested soon.

\section{References}

[1] Dulaimi, M., Ling, Y. F., Ofori, G. \& De-Silva, N., Enhancing integration and innovation in construction. Building Research \& Information, 30(4), pp. 237-247, 2002.

[2] Mitropoulos, P. \& Tatum, C., Forces driving adoption of new information technologies. Construction Engineering \& Management, 126(5), pp. 340348, 2000.

[3] Elmualim, A. \& Gilder, J., BIM: innovation in design management, influence and challenges of implementation. Architectural Engineering \& Design Management, 10(3/4), pp. 183-199, 2014. 
[4] Eadie, R., Odeyinka, H., Browne, M., McKeown, C. \& Yohanis, M., An analyses of drivers for adoption of Building information modeling. Information technology in construction, 18, pp. 338-352, 2013.

[5] Kimoto, K., Endo, K., Iwashita, S. \& Fujiwara, M., The application of PDA as a mobile computing system on construction management. Automation in construction, 14, pp. 500-511, 2005.

[6] Kim, Y. S., Oh, S. W., Cho, Y.K.\& Seo, J.W., A PDA and wireless webintegrated system for quality inspection and defect management of apartment housing projects. Automation in construction, 17(2), pp. 163-179, 2008.

[7] Solihin, W. \& Eastman, C., Classification of rules for automated BIM rule checking development. Automation in construction, 53(6), pp. 69-82, 2015.

[8] Fard, M, G., Bohn, J., Teizer, J., Savarese, S. \& Mora, F, P., Evaluation of image modelling and laser scanning accuracy for emerging automated performance monitoring techniques. Automation in construction, 20, pp. 1143-1155, 2011.

[9] Egan, J. Rethinking construction (Chapter 2). Our ambition for UK construction. London, pp. 1-37, 1998.

[10] Wang, X., Love, P. E., Kim, M. J., Park, C.S., Sing, C.P. \& Hou, L., A conceptual framework for integrating building information modeling with augmented reality. Automation in construction, 34, pp. 37-44, 2013.

[11] Bosché, F., Plane--based registration of construction laser scans with 3D/4D building models. Advanced Engineering Informatics, 26, pp. 90-102, 2012.

[12] Meza, S., Turk, Z. \& Dolnec, M., Component based engineering of a mobile BIM-based augmented reality system. Automation in construction, 42(1), pp. 1-12, 2014.

[13] Davies, R. \& Harty, C., Implementing 'Site BIM': A case study of ICT innovation on a large hospital project. Automation in construction, 30(1), pp. 15-24, 2013.

[14] El-Omari, S. \& Moselhi, O., Integrating automated data acquisition technologies for progress reporting of construction projects. Automation in construction, 20, pp. 699-705, 2011.

[15] Han, K. K. \& Fard, M. G., Appurtenance-based material classification for monitoring of operation-level construction progress using 4D BIM and site photologs. Automation in construction, 53(6), pp. 44-57, 2015.

[16] Han-bin, L. \& Chao-hua, X., Research on BIM-based drawings query and feedback system with smart hand-held devices. Procedia engineering, 85, pp. 351-357, 2014.

[17] Kwon, O. S., Park, C. S. \& Lim. C.R., A defect management system for reinforced concrete work utilizing BIM, image-matching and augmented reality. Automation in construction, 46(9), pp. 74-81, 2014.

[18] Riaz, Z., Arslan, M. \& Azhar, S., CoSMoS: A BIM and wireless sensor based integrated solution for worker safety in confined spaces. Automation in construction, 45(8), pp. 96-106, 2014. 
[19] Lorenzo, T.M., Benedetta, B., Manuele, C. \& Davide, T., BIM and QRcode. A synergic application in construction site management. Procedia engineering, 85, pp. 520-528, 2014.

[20] Madden, L., Professional Augmented Reality Browsers for Smartphones: Programming for Junaio, Layar, and Wikitude. Chichester, West Sussex: Wiley Pub. Inc., 2011.

[21] Azuma, R., A survey of augmented reality, presence: Teleoperators and virtual environments, 6(4), pp. 355-385, 1997.

[22] Jiao, Y., Zhang, S., Li, Y., Wang, Y. \& Yang, B., Towards cloud augmented reality for construction application by BIM and SNS integration. Automation in construction, 33, pp. 37-47, 2013.

[23] Ness, D., Swift, J., Ranasinghe, D. C., Xing, K. \& Soebarto, V., Smart steel: new paradigms for the reuse of steel enabled by digital tracking and modelling. Cleaner Production. pp. 1-12, 2014.

[24] Björk, A., Erlandsson, M., Hakli, J., Jaakkola, K., Nilsson, A., Nummila, K., Puntananen, V.\& Sirkka, A., Monitoring environmental performance of the forestry supply chain using RFID. Computers in industry, 62(9), pp. 830-841, 2011.

[25] Taylor, M., Coady, S. \& Chesser, J., Radio frequency identification (RFID) and building information modeling (BIM): Integrating the lean construction process. Proc. of the $12^{\text {th }}$ Int. Conf. Civil structure and engineering, Funchail: Portugal, pp. 1-4, 2009.

[26] Finkenzelle, K., RFID Handbook: Radio Frequency Identification fundamentals and applications, John Wiley \& Sons, New York, 1999.

[27] Saidi, K. S., Cheok, G., Franaszek, M., Brown, C., Swerdlow, J., Lipman, R., Katz, M. \& Goodrum, P., Development and use of the NIST intelligent and automated construction job site testbed. National institute of Standards and Technology, 2011.

[28] Brilakis, I., Fathi, H., Rashidi, A., Progressive 3D reconstruction of infrastructure with videogrammetry. Automation in construction, 20(7), pp. 884-895, 2011.

[29] Chen, L. \& Luo, H., A BIM-based construction quality management model and its applications. Automation in construction, 46, pp. 64-73, 2014.

[30] Chen, K., Lu, W., Peng, Y., Rowlinson, S. \& Huang, G.Q., Bridging BIM and building: From a literature review to an integrated conceptual framework. International journal of project management, 2015. 